\title{
INCIDÊNCIA DE CAÇA DENTRO DE UMA UNIDADE DE CONSERVAÇÃO DE PROTEÇÃO INTEGRAL: DADOS PRELIMINARES DE ESTUDO DE CASOS COMO FORMA DE CONTROLE À CAÇA.
}

\author{
Vera Sabatini ${ }^{1}$ \\ Ernesto Pedro Dickfeldt ${ }^{2}$ \\ Paulo Roberto de Oliveira ${ }^{3}$
}

E-mail de contato

\section{vera.sabatini@gmail.com}

RESUMO

A ameaça da fauna silvestre na Mata Atlântica ocorre pela grave ameaça dos seus hábitats e pela caça. Apesar de criminalizada por lei, a caça de animais silvestres ainda faz parte da nossa cultura, assim como a captura de aves para animais de estimação. O objetivo deste estudo é averiguar a ocorrência de caça no Parque Estadual Vassununga, quantificando a frequência, local e as espécies de animais silvestres de acordo com o tipo de captura para ser estabelecido um protocolo de atuação eficaz na fiscalização. O monitoramento ocorreu em dois fragmentos do parque, tendo início em 2013. No fragmento Maravilha, até o momento, foram realizadas dez incursões num mesmo transecto sendo encontrados 11 jiraus. Os levantamentos no fragmento Pé-de-Gigante foram realizados três locais distintos não sendo encontrados vestígios de caça. No fragmento Capetinga Oeste foi detectada a caça de ave canora (Saltator similis) pela apreensão da gaiola com alçapões na borda da mata junto ao carreador de cana-de-açúcar. Diante dos

Fundação para a Conservação e a Produção Florestal do Estado de São Paulo vera.sabatini@gmail.com

${ }^{2}$ Instituto Florestal do Estado de São Paulo- ernesto.dickfeldt@terra.com.br

${ }^{3}$ Instituto Florestal do Estado de São Paulo 
resultados preliminares, podemos concluir que há necessidade de uma fiscalização intensiva tanto no entorno quanto no interior das matas dos fragmentos.

Palavras-chave: caça; espécie cinegética; monitoramento de caça.

\section{INTRODUÇÃO}

A Mata Atlântica é uma das áreas mundiais prioritárias para a conservação, tanto pelo nível de biodiversidade e endemismo das espécies (com 73 mamíferos endêmicos) como pela grave ameaça de seus hábitats (Myers et al., 2000). Devido o crescimento das cidades, o aumento da malha viária e das áreas cultivadas, a degradação de seus hábitats naturais, principalmente pela fragmentação, tem sido a principal causa do declínio da população de mamíferos nesse bioma. No entanto, a ameaça da fauna silvestre ocorre, também, pela caça ilegal nas áreas de florestas que restaram da Mata Atlântica. Vários estudos têm demonstrado um declínio acentuado nas populações regionais onde a caça de subsistência ocorre (Chiarello, 2000; Peres, 2000). No entanto, pouco se sabe sobre a pressão de caça das populações de animais silvestres no interior do Estado de São Paulo.

Apesar de criminalizada por lei (Lei n.9.605, de 12 de fevereiro de 1998), a caça de animais silvestres como prática esportiva e para subsistência humana ainda faz parte da nossa cultura, assim como a captura de aves para animais de estimação. As ocorrências de caça mostram que mesmo as espécies listadas como ameaçadas no estado de São Paulo (Decreto Estadual n.60.132, 7 de fevereiro de 2014) são alvo de caçadores, conforme tem sido noticiado pela mídia (http://www.portoferreirahoje.com.br/noticia/notícias regionais).

Com este projeto, pretende-se levantar os locais preferidos para a caça ilegal dentro uma Unidade de Conservação (UC) de Proteção Integral relacionandoos com as espécies mais procuradas e, a partir desses dados, estabelecer um protocolo de atuação eficaz na fiscalização desta Unidade. No presente estudo são apresentados dados preliminares de ocorrência de caça. 


\section{OBJETIVO}

O objetivo deste estudo é averiguar a ocorrência ou não de caça dentro de uma Unidade de Conservação (UC) de Proteção Integral, quantificando a sua frequência, local e as espécies de animais silvestres de acordo com o tipo de captura. Com esses resultados, pretende-se estabelecer um protocolo de atuação eficaz na fiscalização da UC de acordo com as preferências dos locais de caça e das espécies cinegéticas.

\section{METODOLOGIA}

\section{1. Área de Estudo:}

O trabalho está sendo realizado em uma unidade de conservação de proteção integral (Lei 9.985/2.000), o Parque Estadual de Vassununga criado pelo Decreto Estadual no 52.546, de 26 de outubro de 1970 no município de Santa Rita do Passa Quatro/SP. A área total é de 2.071,42ha divididos em cinco fragmentos de Floresta Estacional Semidecidual: Capetinga Leste $(231,06 \mathrm{ha})$; Capetinga Oeste (331,24ha); Praxedes (152,50ha); Maravilha (131,52ha) e Capão da Várzea (12,18ha); e um fragmento de Cerrado: Pé-de-Gigante (1.212,92ha) (Figura 1). Os fragmentos estão isolados numa matriz de cana-de-açúcar e eucalipto, sendo que possuem fácil acesso por estradas asfaltadas ou de terra, com a rodovia Anhanguera (SP-330) confrontando um dos lados de dois fragmentos (Capetinga Leste e Capetinga Oeste). O fragmento Maravilha fica na margem do rio MogiGuaçu. O clima da região é classificado como Cwa: quente com inverno seco, com temperatura média maior que $22^{\circ} \mathrm{C}$ no mês mais quente e menor que $17^{\circ} \mathrm{C}$ no mês mais frio. 
Figura 1: Fragmentos que formam o Parque Estadual de Vassununga, totalizando uma área de 2.071,42ha, no município de Santa Rita do Passa Quatro, SP. O parque é administrado pela Fundação Florestal, vinculada a Secretaria do Meio Ambiente do Estado de São Paulo.

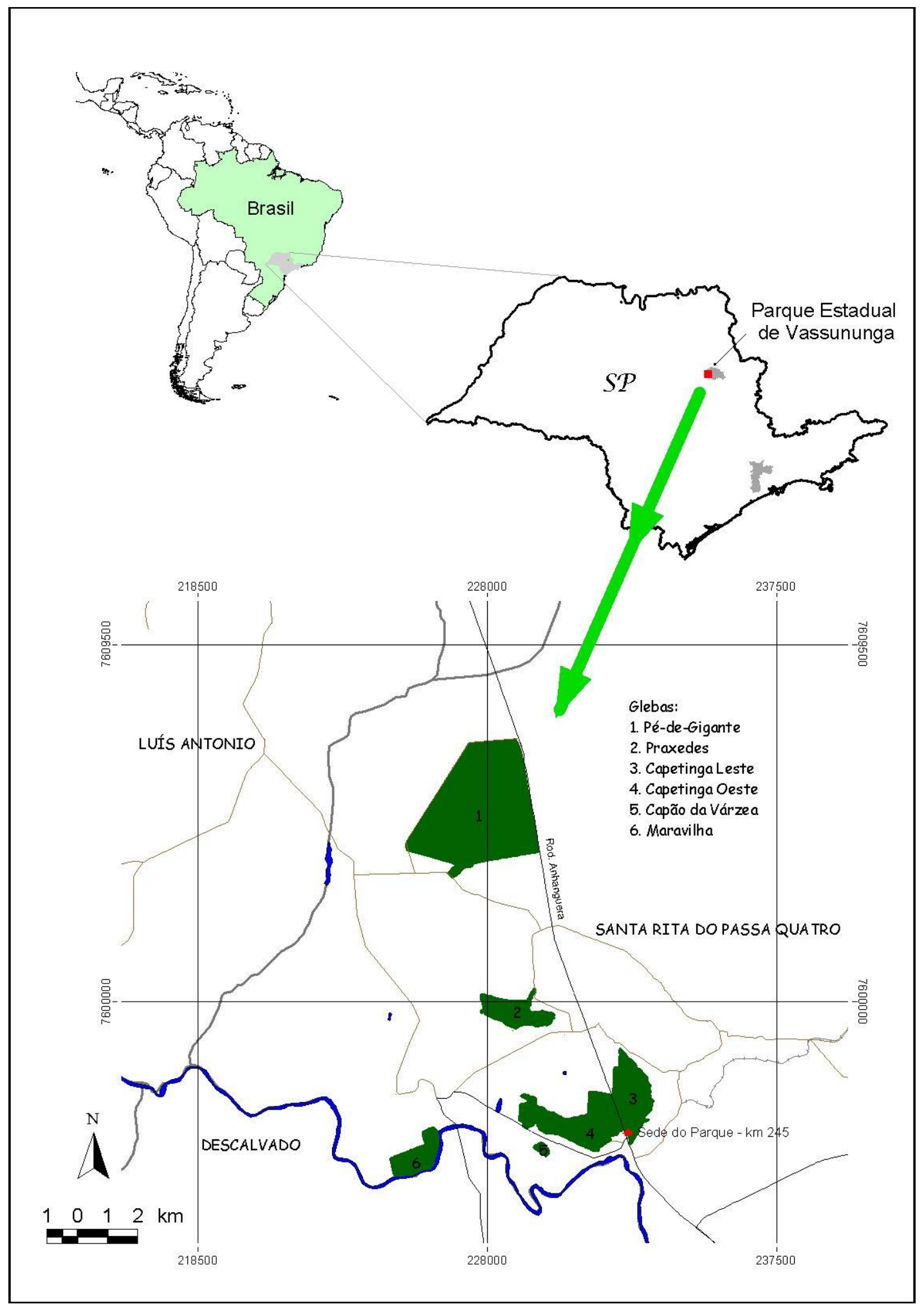




\subsection{Coleta de dados:}

Os dados foram coletados em dois fragmentos (Maravilha e Pé-de-Gigante), em transectos demarcados por GPS, sendo percorridos uma vez a cada 30 dias. A escolha do fragmento Maravilha para se iniciar as observações das evidências de caça foi em decorrência de informações de uma pesquisadora e um funcionário do Parque que haviam constatado um jirau ("poleiro") nas margens do rio Mogi-Guaçu, em outubro de 2013. O fragmento de cerrado, Pé-de-Gigante, foi o segundo fragmento escolhido, porque neste local já foram constatados vestígios de caça por antigos funcionários do Parque (Dickfeldt, comunicação pessoal).

Os locais dos transectos, para serem averiguadas as evidências de ação de caça na UC, foram escolhidos de acordo com os seguintes critérios: (1) proximidade de cursos d'água e/ou estradas vicinais; (2) onde já foram encontrados vestígios de caça por funcionários do parque ou pesquisadores com projetos nos fragmentos; (3) proximidade das espécies frutíferas, durante o período de frutificação, apreciadas pela fauna cinegética: (jatobás, Hymenaea courbaril; jenipapos Genipa americana; jaracatiás, Jacaratia spinosa); (4) onde há trilhas clandestinas nos fragmentos; (5) onde costumam ser encontrados cachorros de caça.

$\mathrm{Na}$ UC existe vigilância motorizada que circunda os fragmentos no período diurno, portanto, as apreensões e constatações de caça registradas pelos vigias são anotadas após a verificação no local. As coordenadas geográficas dos locais com os vestígios da ação dos caçadores ("poleiros" ou jiraus; cevas; latidos de cães; armadilhas) encontrados são demarcados num mapa. As cevas são retiradas dos locais quando encontradas, porém, os jiraus são deixados nas duas primeiras vezes e retirados nas seguintes.

\section{RESULTADOS}

No fragmento Maravilha, até o momento, foram realizadas dez incursões num mesmo transecto, sendo dois monitoramentos em 2013, sete em 2014 e um monitoramento em 2015. O local fica na margem do rio Mogi-Guaçu, sendo que, os locais onde havia os jiraus com as cevas estavam cerca de 100 metros do carreador de cana-de-açúcar e a 20m da margem do rio (Figura 2). O acesso para o interior da 
mata é feito através de um capinzal que fica entre o carreador de cana e a borda da floresta.

Figura 2: Fragmento Maravilha, na margem direita do rio Mogi-Guaçu, indicando o transecto percorrido (em vermelho) e as coordenadas geográficas na entrada da mata $\left(21^{\circ} 44^{\prime} 17,42^{\prime \prime} S\right.$ / 47039'35,79" O).

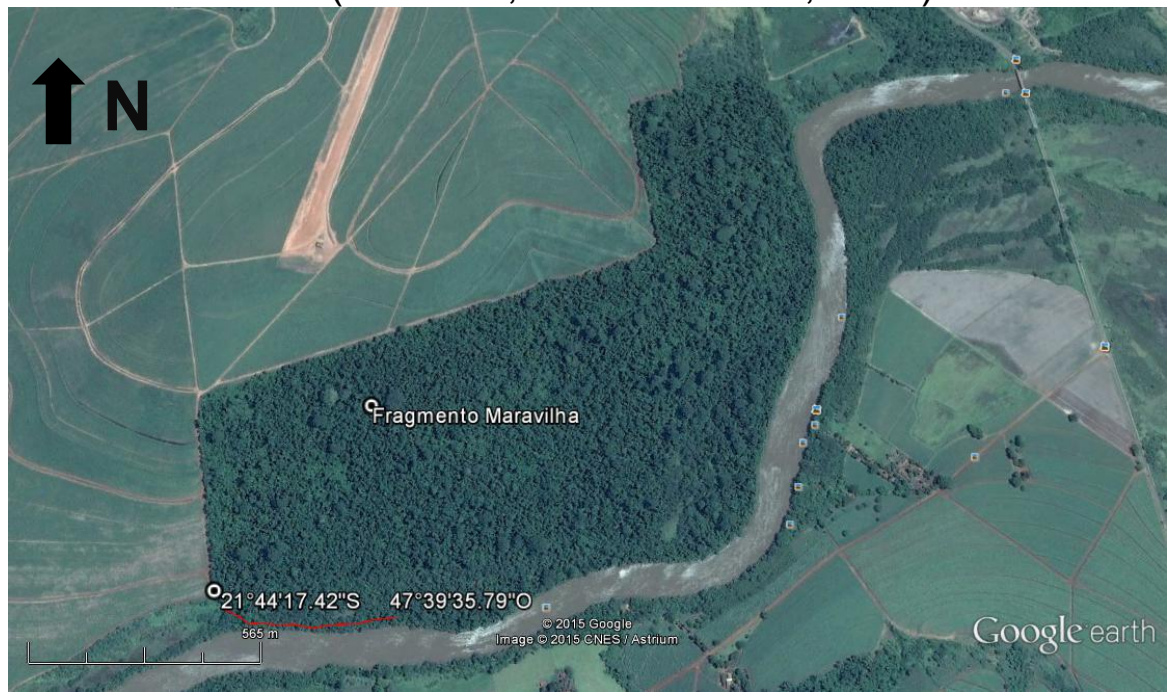

Fonte: Google Earth, 2015.

No total havia 11 jiraus na mesma trilha desta gleba. Em 2013, foram encontrados dois jiraus no local, um em cada incursão. Em 2014 foram feitas sete monitoramentos sendo encontrados oito jiraus, sendo que em três das incursões havia dois jiraus construídos no mesmo local distantes $10 \mathrm{~m}$ um do outro. Nas ocasiões nas quais os jiraus não foram destruídos e retirados das árvores houve reincidência da ceva no mesmo jirau e quando o jirau foi destruído e retirado, não foi encontrado jirau ou ceva naquele ponto de caça na incursão seguinte (Tabela 1). Em 2015, foi realizada uma incursão sendo encontrados uma ceva e um jirau construído no mesmo ponto de 2013.

As iscas utilizadas para cevar eram frutas (abacate e maracujá) e espigas de milho seco, depositadas no solo e amarradas com arame no tronco de uma árvore a cerca de $3 \mathrm{~m}$ dos jiraus. Os jiraus foram construídos por troncos de árvores, de aproximadamente $8 \mathrm{~cm}$ de diâmetro e 1,5m de comprimento, pregados no tronco das árvores maiores (tronco com $50 \mathrm{~cm}$ de diâmetro) formando uma escada (Figura 3). Árvores próximas com 8 a $10 \mathrm{~cm}$ de diâmetro estavam cortadas, provavelmente para usarem os galhos para serem construídos os jiraus. 
Tabela1: Pontos de caça, com jirau e ceva, encontrados no fragmento Maravilha próximos à margem do rio Mogi-Guaçu em uma mesma trilha.

\begin{tabular}{|c|c|c|c|c|c|}
\hline Data & $\begin{array}{c}\text { Quantidade } \\
\text { de jirau }\end{array}$ & $\begin{array}{l}\text { Coordenada } \\
\text { Geográfica }\end{array}$ & $\begin{array}{c}\text { Situação } \\
\text { Jirau }\end{array}$ & Recorrência & Ceva \\
\hline $10 / 2013$ & 01 & $\begin{array}{l}21^{\circ} 44^{\prime} 19,5 " \mathrm{~S} / \\
47^{\circ}-39^{\prime} 31,82^{\prime \prime O}\end{array}$ & deixado & - & $\operatorname{sim}$ \\
\hline $11 / 2013$ & 01 & $\begin{array}{l}21^{\circ} 44^{\prime} 19,5 " \mathrm{~S} / \\
47^{\circ}-39^{\prime} 31,82 " \mathrm{O}\end{array}$ & deixado & $\operatorname{sim}$ & $\operatorname{sim}$ \\
\hline $02 / 2014$ & 01 & $\begin{array}{l}21^{\circ} 44^{\prime} 19,5 " \mathrm{~S} / \\
47^{\circ}-39^{\prime} 31,82^{\prime \prime O}\end{array}$ & deixado & sim & $\operatorname{sim}$ \\
\hline $03 / 2014$ & 02 & $\begin{array}{c}21^{\circ} 44^{\prime} 19,5 " \mathrm{~S} / \\
47^{\circ} 39 ' 31,82^{\prime \prime O} \\
\mathrm{e} \\
21^{\circ} 44^{\prime} 19,40 " \mathrm{~S} / \\
47^{\circ} 39^{\prime} 35,01^{\prime \prime} \mathrm{O}\end{array}$ & deixado & novo a $20 \mathrm{~m}$ & $\operatorname{sim}$ \\
\hline $05 / 2014$ & 02 & $\begin{array}{c}21^{\circ} 44^{\prime} 19,5 " \mathrm{~S} / \\
47^{\circ} 39^{\prime} 31,82^{\prime \prime O} \\
\mathrm{e} \\
21^{\circ} 44^{\prime} 19,40^{\prime \prime S} / \\
47^{\circ} 39^{\prime} 35,01^{\prime \prime} \mathrm{O}\end{array}$ & deixado & $\operatorname{sim}$ & $\operatorname{sim}$ \\
\hline $06 / 2014$ & 02 & $\begin{array}{c}21^{\circ} 44^{\prime} 19,5^{\prime \prime S} / \\
47^{\circ} 39^{\prime} 31,82^{\prime \prime O} \\
\mathrm{e} \\
21^{\circ} 44^{\prime} 19,40^{\prime \prime S} / \\
47^{\circ} 39^{\prime} 35,01^{\prime \prime} \mathrm{O}\end{array}$ & retirado & $\operatorname{sim}$ & $\operatorname{sim}$ \\
\hline 07/2014 & ausente & & & - & - \\
\hline 08/2014 & 01 & $\begin{array}{l}21^{\circ} 44^{\prime} 19,25 " \mathrm{~S} / \\
47^{\circ} 39^{\prime} 34,47^{\prime \prime O}\end{array}$ & retirado & novo a $10 \mathrm{~m}$ & ausente \\
\hline 09/2014 & ausente & & & - & - \\
\hline $5 / 2015$ & 01 & $\begin{array}{l}21^{\circ} 44^{\prime} 19,5^{\prime \prime S} / \\
47^{\circ} 39^{\prime} 31,82^{\prime \prime O}\end{array}$ & retirado & $\begin{array}{c}\text { sim } \\
\text { mesmo local } \\
\text { de } 2013\end{array}$ & $\operatorname{sim}$ \\
\hline
\end{tabular}


Figura 3: Fotografia do jirau ou "poleiro" encontrado no fragmento Maravilha em maio de 2015, na coordenada geográfica 21ํ4'19,5"S/ 4739'31,82"O.

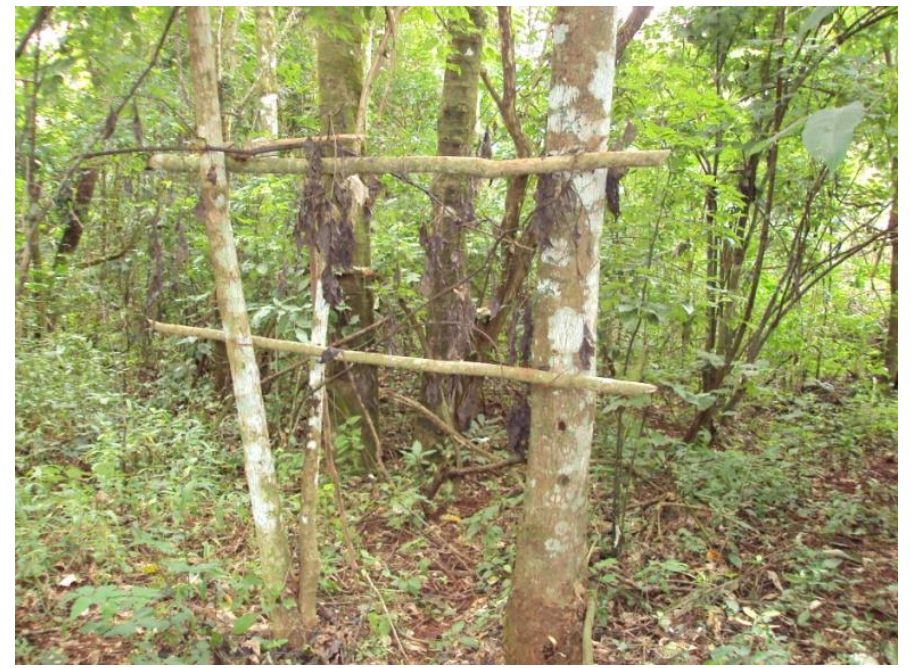

Fonte: Parque Estadual Vassununga, Vera Sabatini.

Os levantamentos no Pé-de-Gigante iniciaram em abril de 2015, tendo sido realizados três levantamentos em locais distintos. Duas trilhas, na parte sul do fragmento e a terceira trilha na face norte. Não foram encontrados vestígios de caça nos locais observados (Figura 4).

Figura 4: Fragmento Pé-de-Gigante, com os três transectos (em vermelho). As coordenadas geográficas indicam o início de cada transecto nos carreadores que circundam

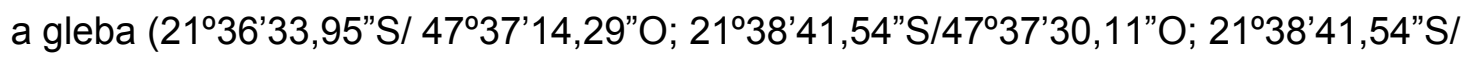
$47^{\circ} 37^{\prime} 30,11^{\prime \prime}$ )

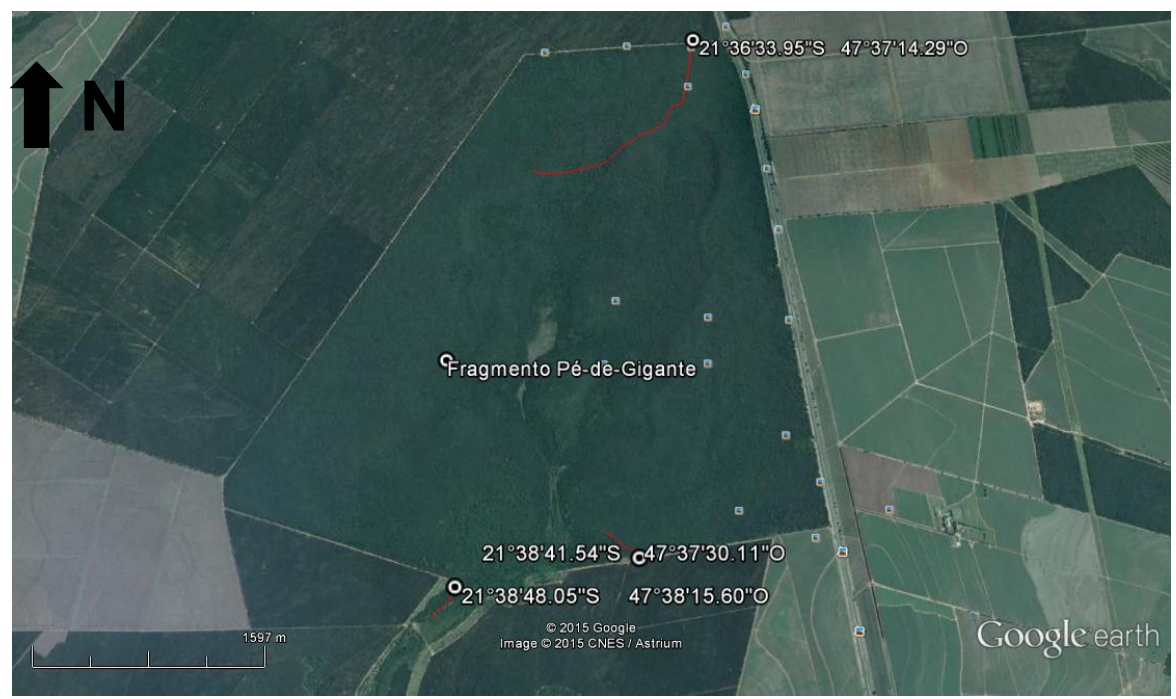

Fonte:Google Earth, 2015. 
Em novembro de 2014 houve uma apreensão de caça de gaiola no fragmento Capetinga Oeste, na coordenada geográfica $21^{\circ} 43^{\prime} 23,78^{\prime \prime} \mathrm{S}$ e $47^{\circ} 37^{\prime} 10,12^{\prime \prime}$. O vigia motorizado abordou um indivíduo saindo da mata, quando fazia a ronda pelo carreador que contorna tal fragmento. Uma gaiola, contendo um espécime de Saltator similis (trinca-ferro), e quatro alçapões foram encontrados dentro da mata. O pássaro foi libertado e as armadilhas destruídas, depois de ser providenciado um boletim de ocorrência na delegacia da polícia civil, devido à fuga do caçador.

\section{DISCUSSÃO}

Os locais de caça, tanto no fragmento Maravilha onde foram encontrados jiraus como na Capetinga Oeste onde estava a gaiola com o trinca-ferro (usado como chamariz), estavam próximos aos carreadores de cana-de-açúcar, locais de fácil acesso e de fuga. Conforme mostrado nesses resultados, a fragmentação florestal acarretou o acesso aos locais de caça pelas estradas e carreadores. $\mathrm{Na}$ gleba Maravilha os jiraus encontrados estavam próximos, também, das margens do rio Mogi-Guaçu, sendo, portanto, outro local de fácil acesso com utilização de embarcações. Esta possibilidade foi confirmada pela presença de pegadas humanas na margem, indicando que o acesso aos pontos de caça neste fragmento também foi feito por barco.

Apesar de no passado já terem ocorrido registros de caça no fragmento Péde-Gigante (conforme o relato pessoal de Dickfeldt), não foram encontrados vestígios de caça neste local. Um transecto que fica na parte norte deste fragmento é uma trilha usada por pesquisadores e apesar dessa intervenção é um local onde algumas espécies de animais foram avistadas recentemente, como a onça-parda (Puma concolor) e tamanduá bandeira (Myrmecophaga tridactyla), por funcionários do Parque. Provavelmente, a maior movimentação nesta área por pesquisadores e funcionários pode afugentar os caçadores deste local, embora a entrada da trilha esteja numa estrada vicinal de grande movimentação.

Diante dos resultados obtidos, há necessidade de se reforçar a vigilância no entorno dos fragmentos devido à facilidade de acesso oferecida pelas estradas e carreadores, independente do método usado pelo caçador e da espécie alvo. 
Principalmente, nos locais dos fragmentos pouco frequentados por funcionários ou pesquisadores. No entanto, no caso do fragmento que margeia o rio Mogi-Guaçu a vigilância do Parque Estadual Vassununga deveria ser reforçada pela via fluvial embarcada. A vigilância no interior da mata dos fragmentos, também, deve ser reforçada, pois, quando os jiraus foram destruídos não ocorreu reincidência na construção de novos jiraus nos mesmos locais. Podemos concluir, portanto, que a fiscalização intensiva inibe a ação dos caçadores. Entretanto, essa ação deveria ser tanto no entorno quanto no interior das matas.

\section{REFERÊNCIA BIBLIOGRÁFICA}

CHIARELLO, Adriano G. Influência da caça ilegal sobre os mamíferos e aves das matas de tabuleiro do norte do estado do Espírito Santo. Boletim do Museu de Biologia Mello Leitão, Série 11/12, 2000. p. 229-247.

MYERS, Norman et al. Biodiversity hotspots for conservation priorities. Nature, 2000. 403, 853858.

PERES, Carlos A. Evaluating the impact and sustainability of subsistence hunting at multiple Amazonian forest sites. Robinson, J. G. \& Bennett, E. L. (eds.) Hunting for sustainability i tropical forests. New York. Columbia University. 2000. p. 83-115.

\section{AGRADECIMENTOS:}

Agradecemos o apoio na observação de campo do funcionário do Parque Estadual Vassununga, Waldonésio Borges Nascimento, e da pesquisadora Ms. Carla Gestich, e do apoio logístico de transporte da gestora do P. E. de Porto Ferreira, Sônia Aparecida de Souza Evangelista. 